Research, part of a Special Feature on Landscape Scenarios and Multifunctionality - Making Land Use Assessment Operational

\title{
Ex Ante Impact Assessment of Policies Affecting Land Use, Part B: Application of the Analytical Framework
}

\author{
$\underline{\text { Katharina Helming }}^{1}$, Katharina Diehl ${ }^{1}$, Tom Kuhlman ${ }^{2}$, Torbjörn Jansson ${ }^{3}$, Peter H. Verburg ${ }^{4}$, \\ Martha Bakker $^{5}$, Marta Perez-Soba ${ }^{5}$, Laurence Jones ${ }^{6}$, Pieter Johannes Verkerk ${ }^{7}$, Paul Tabbush,

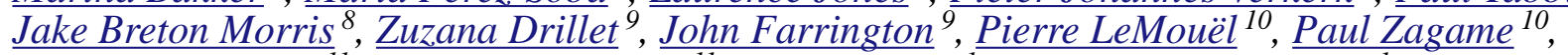 \\ Tomasz Stuczynski $^{11}$, Grzegorz Siebielec ${ }^{11}$, Stefan Sieber ${ }^{1}$, and Hubert Wiggering $^{1}$
}

\begin{abstract}
The use of science-based tools for impact assessment has increasingly gained focus in addressing the complexity of interactions between environment, society, and economy. For integrated assessment of policies affecting land use, an analytical framework was developed. The aim of our work was to apply the analytical framework for specific scenario cases and in combination with quantitative and qualitative application methods. The analytical framework was tested for two cases involving the ex ante impact assessment of: (1) a European Common Agricultural Policy (CAP) financial reform scenario employing a modeling approach and combined with a comprehensive indicator analysis and valuation; and (2) a regional bioenergy policy scenario, employing a fully participatory approach. The results showed that European land use in general is less sensitive to changes in the Common Agricultural Policy, but in the context of regions there can be significant impacts on the functions of land use. In general, the implementation of the analytical framework for impact assessment proved to be doable with both methods, i.e., with the quantitative modeling and with the qualitative participatory approach. A key advantage of using the system of linked quantitative models is that it makes possible the simultaneous consideration of all relevant sectors of the economy without abstaining from a great level of detail for sectors of particular interest. Other advantages lie in the incontestable character of the results. Based on neutral, existing data with a fixed set of settings and regions, an absolute comparability and reproducibility throughout Europe can be maintained. Analyzing the pros and cons of both approaches showed that they could be used complementarily rather than be seen as competing alternatives.
\end{abstract}

Key Words: analytical framework; discussion tools; DPSIR framework; ex ante impact assessment; landuse change; model-based tools; participatory assessment tools; policy development; sustainability

\section{INTRODUCTION}

Policy making in the area of land use in Europe aims at balancing the correlation between economic growth and environmental degradation, while at the same time fostering social cohesion (Council of the European Union 2006). In this regard, the understanding of complex future implications of policy making has become a high political priority in Europe (Volkery and Ribeiro 2007). Foresight of land-use change and its impacts can help to better inform policy decisions, because the success of tomorrow's situation depends on decisions made today (Verburg et al. 2006). The European Union Sustainable Development Strategy explicitly reinforced the importance of using a high-quality, ex ante impact assessment (IA) as a tool to improve policy making (Council of the European Union 2006). The strategy states that all major policy decisions should be based on proposals that have undergone an impact assessment, whereby equal consideration should be given to the social, environmental, and economic dimensions of sustainable development. 
In response to the Göteborg commitment to implement the Sustainable Development Strategy, the European Commission started the systematic development of an integrated, centralized impact assessment framework. Internal guidelines, first published in 2002 (Impact Assessment in the Commission-Guidelines and the Handbook for Impact Assessment in the Commission-How to do an Impact Assessment), set out the step-by-step procedures involved in an impact assessment. Since then the guidelines have been regularly updated with new insights and guidance in response to developments in the policy and impact assessment fields (European Commission 2005, 2009). The aim was to be able to estimate the environmental, economic, and social impacts of a proposed policy in order to provide political decision makers with comprehensive and clear information of possible consequences, trade-offs, and other side effects.

To address the complexity of interactions between environment, society, and economy, the use of science-based instruments and tools for sustainability assessment has increasingly gained focus (McIntosh et al. 2007, Thiel 2009, Sieber et al. 2010). Carpenter et al. (2006) specify the purpose of an assessment as synthesizing scientific information to inform policy but not to prescribe it. The requirements for such methods and tools in the process of impact assessment were further described by Bäcklund (2009): to provide accurate estimates about impacts, to increase integration between sectors, to serve as communication and information tools, and to provide a basis for decision making.

For integrated assessment of policies affecting land use, this implies the simultaneous consideration of all spatially relevant aspects of those economic sectors and human activities that are linked to land (Helming et al. 2008). These include agriculture and forestry as main sectors, while transport and energy infrastructure, rural tourism, and nature conservation are considered "regulatory activities" that occupy land. Because all these sectors and activities compete for land resources, any policy change affecting one of these land uses has the potential to induce changes in the other sectors. Particularly, transnational policies can substantially influence market regimes in all affected sectors (Plummer 2009).

Several recent interdisciplinary studies relate to ex ante assessments of future land-use change scenarios based on a number of social, economic, and environmental indicators (Busch 2006, Rounsevell et al. 2006, Ewert et al. 2009, Prins et al. 2011, Verburg et al. 2010). A comprehensive review of recent land-use scenario models is provided by Schaldach and Priess (2008). Compared to earlier disciplinary studies, these studies provided substantial improvement in the understanding of coupled human-environmental systems in the area of land use. The usefulness of such studies for informing the policy-making process of ex ante impact assessment is still hindered by at least three factors: (1) the complexity, and, related to this, the intransparency and inflexibility of the sophisticated modeling system; (2) the lack of sensitivity to the policy context; and (3) the insufficient integration of the indicator assessment into a sustainability valuation approach (Helming et al. 2011a). To narrow these gaps a new analytical framework for ex ante impact assessment of policies affecting land use was developed and described (Helming et al. 2011b). The framework includes scenario development of policy-induced land-use changes and subsequent valuation of landuse change impacts in the context of regional sustainable development (Fig. 1). The framework is described in detail in Helming et al. (2011b).

In brief, the framework follows the DPSIR concept (drivers, pressures, states, impacts, responses). There are two sets of external drivers, i.e., those drivers that span a future socioeconomic and technological reference situation, and policy drivers. The consequential land-use change is defined as the pressure that is affected by both mentioned drivers. The role of states is taken by numerous social, economic, and environmental parameters that are affected by land-use changes and that characterize the environmental and socioeconomic situation of an area. They are quantified by indicators. Sustainability impacts are meant to be derived by aggregating these indicators and translating them into services to society, which are provided through land use. They can then be valued by experts and stakeholders against sustainability perceptions. Responses are meant to be actions taken by decision-makers following results of the impact assessment. These are exogenous to the impact assessment and are therefore not taken up here. The framework represents the basis for the development of tools for assessing environmental, social, and economic effects of multifunctional land use in European regions. 
Fig. 1. Illustration of the integrated framework for policy impact assessment, as described in Helming et al. (2011b).

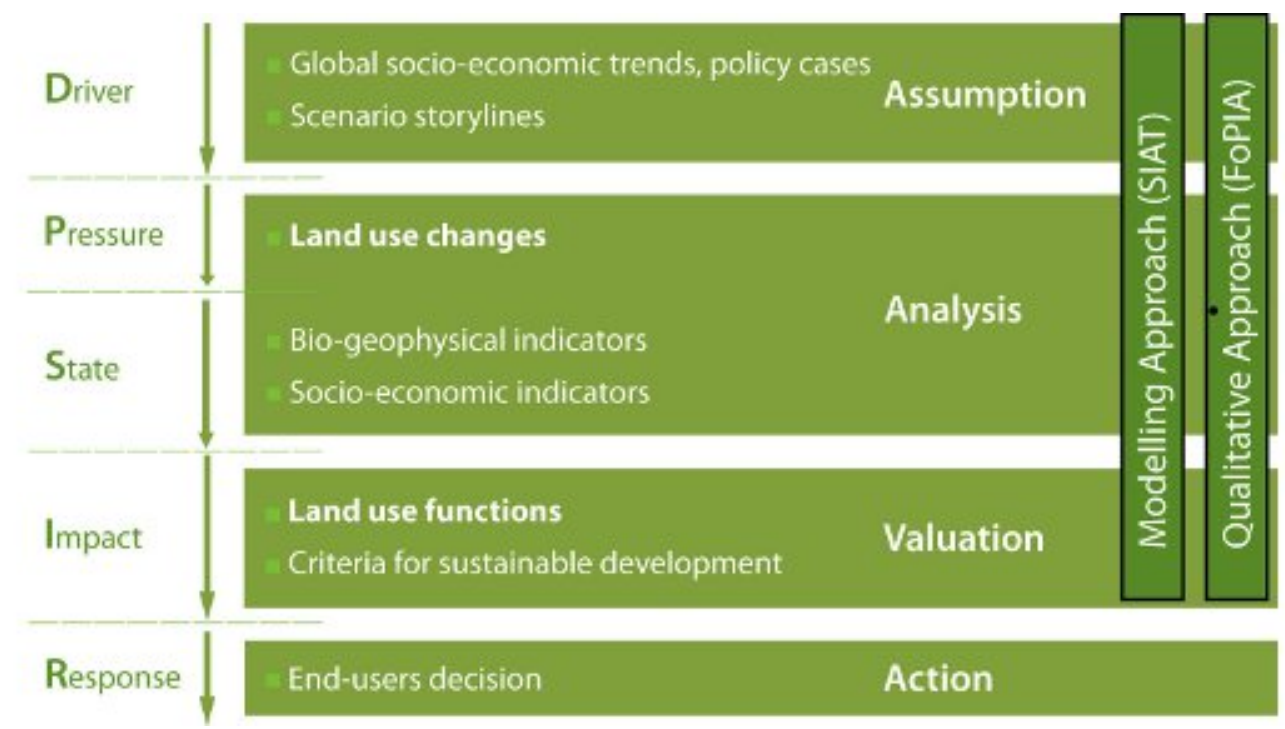

The aim of our work was to illustrate the analytical framework for specific scenario cases and in combination with quantitative and qualitative application methods. In particular, we wanted to:

1. analyze the applicability of the framework for developing policy-relevant discussion and decision support tools for impact assessment; and

2. present and discuss illustrative results with particular relevance to the following three linked research questions:

What kind of land-use changes are to be expected as a consequence of policy intervention?

3. Where will the expected changes take place?

4. Will the expected changes matter (valuation of changes) in terms of regional sustainable development?

The analytical framework was tested for two cases involving the ex ante impact assessment of: (1) a European Common Agricultural Policy (CAP) financial reform scenario applied to the area of the European Union, and employing a modeling approach combined with a comprehensive indicator analysis and valuation, and (2) a bioenergy policy scenario applied to a postindustrial region in Silesia (Poland), and employing a fully participatory approach.

For both test cases, the scenario background and methodology of the analytical framework are described in the methods section. In the results section, simulated land-use change scenarios and exemplary social, economic, and environmental impacts are presented. The outcomes are valuated in light of regional sustainable development. It is important to note that the presented results show only a small sample of the suite of simulated results. The purpose here is to provide an overview of the general applicability of the analytical framework rather than to provide a comprehensive overview of simulated results. The methodological applications of the approach are discussed, and its usefulness for ex ante impact assessments is evaluated. The paper concludes with some reflections on the combination and complementarities of quantitative (modelbased) and qualitative (stakeholder-inclusive) analytical approaches to impact assessment within the framework. 


\section{METHODS}

\section{Case Study 1: Common Agricultural Policy financial policy reform scenario applied to the area of the European Union}

In 2005 there was considerable debate in the European Council of Ministers about the long-term European Union budget (known as the financial perspective) for the period 2006 to 2013 . There was strong pressure from several member states to further reduce or even abolish the Common Agricultural Policy, while there was a British proposal to spend the funds that would be released towards achievement of the Lisbon Agenda, i.e., by spending them on research and development. These proposals were unsuccessful, but when decisions need to be taken in 2012 about a new financial perspective for 2013 to 2019, a revision will be a major point of discussion.

The two fundamental scenario options identified for the future Common Agricultural Policy in this study were: (1) to what extent to continue direct income support to farmers as provided under the 2003 reform of the Common Agricultural Policy; and (2) whether or not to abolish the current (already reduced) system of market support measures. If Common Agricultural Policy expenditure were to be reduced, there is the further option of either simply returning the amount saved to the taxpayer, or (as was suggested during the political discussions in 2005) there is the option to redirect the money towards the goals of the Lisbon strategy in order to help make the European Union become a most competitive knowledge-based economy (European Parliament 2000, Rodrigues 2003); this would mean investing it in research and development. Each of these options would, of course, lead to different pathways of economic growth, social change, and environmental sustainability (Håkan 2008). This paper considers the extreme combination of the above, i.e., that of completely abolishing all direct support and market support, unilaterally admitting free trade in agricultural commodities, and redirecting the budget to research and development for all sectors of the economy.

\section{Implementation of the analytical framework: modeling approach combined with a comprehensive indicator analysis}

In this example case, the analytical framework was implemented by using a combination of a macroeconomic model, a land-use model, and sector models (some of which were purpose-built for this approach), thus linking the policy scenarios with the indicator computations (Jansson et al. 2008a, 2009). The policy changes related to Common Agricultural Policy reform were assumed to be implemented in the period 2015 to 2025, and final results were computed for 2025 (Jansson et al. 2008b). All results were evaluated against a reference scenario that presents a calculation of an expected development of land-use conditions for 2025 in the absence of any change in policy intervention (Kuhlman 2008). The major challenge was to derive a trade-off between full coverage of the complexity of causal chain relations in the modeling approach on the one hand, and robust, quick, and transparent calculations on the other. The method followed aimed to capture the reactions of key model results for a preselected range of Common Agricultural Policy budget scenarios by response functions. In that way the outcomes of the response functions could be used as inputs to the indicator computations instead of to the model suite itself. The response functions were econometrically estimated based on the results of a large number of simulation experiments with the full model suite in the development phase (Sieber et al. 2008, Jansson 2009). The outcome was a newly developed metamodeling Sustainability Impact Assessment Tool (SIAT) that could work as an independent webbased application (Verweij et al. 2010).

To achieve this, a linked system of models was developed (Jansson et al. 2008a), as described in Fig. 2.

In the figure, white boxes represent data, whereas dark boxes represent some form of computation models. The arrows represent an information flow. The starting point of the information flow is the set of policy variables available (white box 1). The policy variables are the settings which the user of the system may control in order to explore the impacts of a range of policy changes. The end point of the flow is the set of impact indicators (white box $3)$. The indicator results were computed by indicator functions and model results (white box 2).

Each simulation experiment started with CAPRI (Britz and Witzke 2008), an agricultural sector model. CAPRI used information from the other models, in particular utilizable agricultural area $\left(\mathrm{A}_{\mathrm{a}}\right)$, together with the current policy to compute agricultural production, output prices, and, in particular, land prices $(\lambda)$. This information was 
Fig. 2. Information flow, from policy to indicators, within the modeling system (from Jansson et al. 2008b).
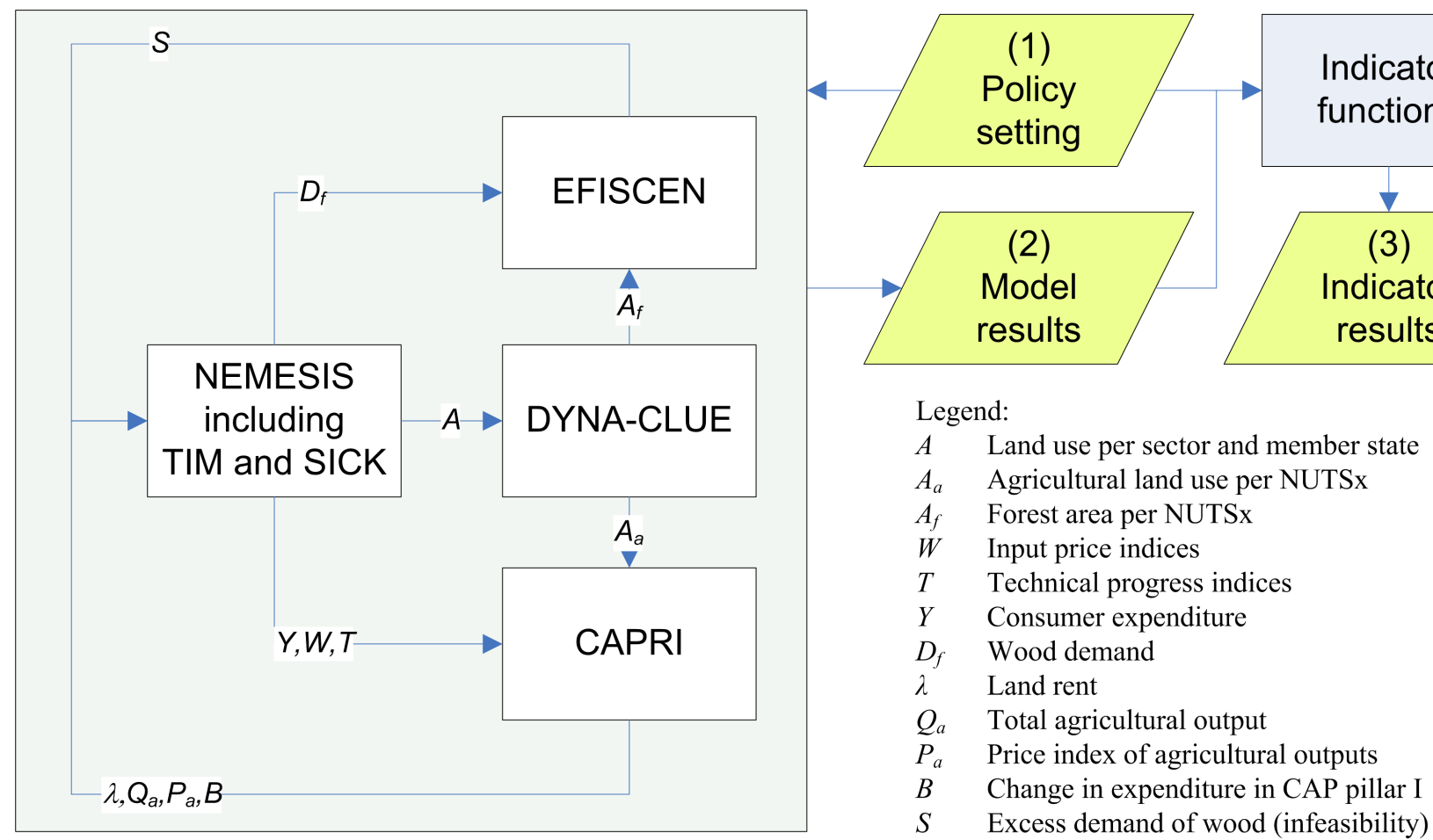

then used in NEMESIS (Brécard et al. 2006), which is a macroeconomic model, to calculate a global balance between land supply and land claims over all sectors that were studied. Equations representing the land claims from the tourism, transportation, and urban sectors were implemented in the NEMESIS model. Agricultural area was determined at a national level by NEMESIS and disaggregated within the countries by DYNA-CLUE, a land-use change model (Verburg and Overmars 2009). These subnational agricultural areas, together with other macroeconomic variables from NEMESIS, were again used by the CAPRI model to assess agricultural sector responses to changes in available land. (Other variables that were computed by NEMESIS and used to shock CAPRI include price indices of variable inputs, change in total factor productivity, and consumer expenditure.) Other variables that were computed by NEMESIS and used to shock CAPRI include price indices of variable inputs, change in total factor productivity, and consumer expenditure. This response is fed back to NEMESIS to solve for a new equilibrium solution of all land balances. Each member state contained one land balance, which required the total land area to be shared among agriculture, forestry, urban land use, transport infrastructure, protected areas (fixed), and land unsuitable for exploitation (fixed). DYNA-CLUE disaggregated the NEMESIS land-use shares into a square-kilometer grid for the area of the European Union to allow location specific impact assessment. EFISCEN (Sallnäs 1990, Schelhaas et al. 2007), a large-scale forest resources model, computed the impacts on wood supply and forest resource development based on demand for wood (from NEMESIS), changes in the forest area (from DYNA-CLUE), and forest management regime. Iterations between the models were repeated until model results converged. Validation of models was performed for each of the models individually. All models have a record of applications and respective documentation (Brécard et al. 2006, Schelhaas et al. 2007, Britz and Witzke 2008, Verburg and Overmars 2009). Robustness of 
the model combination was achieved by computing joint equilibriums using an iterative recalibration approach (Jansson et al. 2008).

An indicator framework was developed for the specific case of land-use impact assessment (Kristensen et al. 2009). On this basis a total for 23 indicators were tested in terms of their suitability to determine distinct environmental, social, and economic impacts resulting from policy-induced land-use changes (Bach et al. 2008; for examples see Jones et al. 2009, Podmanicky et al. 2009, Renetzeder et al. 2009, Scholefield et al. 2009, Verkerk et al. 2009). Indicators were determined for the area of the European Union at NUTS-X administrative level, which is a combination of NUTS-2 and NUTS-3 based on Eurostat's Nomenclature of Territorial Units for Statistics (Eurostat 2010) which subdivides the European member states into units following administrative boundaries (Renetzeder et al. 2008). Indicator determination is described in Bach et al. (2008). A comparative valuation of the indicator results was made possible by aggregating the indicator results into a suite of nine land-use functions (LUF) that are meant to represent goods and services produced through land use in its interaction with the geophysical and socio-cultural capital of the landscape. With the land-use functions, the most relevant societal, economic, and environmental issues of a region are summarized in only nine categories that serve as a basis for sustainability valuation and comparison across regions (PerezSoba et al. 2008). The method for indicator aggregation and the concept of land-use functions is a combination of the ecosystem services concept (Millennium Ecosystem Assessment 2003) and the concept of landscape functions (Bastian et al.2006), as described by Perez-Soba et al. (2008) and Schößer et al. (2010). The method of indicator aggregation towards land-use functions is described in detail in Perez-Soba et al. (2009) and Paracchini et al. (2009). In this study, the comparative valuation of land-use functions was obtained through expert judgements.

\section{Case Study 2: bioenergy policy scenario applied to a postindustrial region in Silesia (Poland)}

The European Union is committed to climate change mitigation and adaptation and, at the same time, to increasing the security of Europe's energy supply-the objectives are laid down in the
Renewable Energy Road Map of the European Union (Commission of the European Communities 2008). The promotion of bioenergy is one of the options discussed. Here, the principal objectives are: (1) quantitative targets for the proportion of bioenergy in the three categories of energy output (transport fuels, electricity, and heat); (2) sustainability of production, and (3) fostering a competitive bioenergy industry (also for export purposes) through technology development.

The transition from a low to a high promotion of bioenergy is addressed by stronger legislation (in the case of biofuel obligations), increased allocations of funding to create a market for bioenergy (fixed price guarantees and tax incentives), and increases in incentives for the cultivation of bioenergy feedstocks (crop subsidies). As such, the implementation of policy instruments promotes both the production of biomass and the consumption of bioenergy. All of these instruments are likely to have impacts on landuse change, whether directly (biomass cultivation promotion measures) or indirectly (legislation and market creation measures).

From the options described above, one case study was selected to explore the impacts of a proposed policy change aimed at the promotion of bioenergy production and consumption on a regional level. This policy change is made up of several components: (1) the setting of a mandatory percentage of biofuel in transport fuels, (2) subsidies for research and development of bioenergy in all its forms, and (3) subsidies (including tax breaks) for the production of heat and electricity from biomass.

\section{Implementation of the analytical framework: employment of a qualitative participatory approach}

A participatory framework (Morris et al. 2011) was applied at a regional level that comprised two principal stakeholder research phases, following the integrated analytical framework shown in Fig. 1: (1) defining policy scenarios (Phase 1), and (2) conducting a sustainability impact assessment of each scenario (Phase 2). The analytical structuring of the FoPIA allowed an iterative approach to assessing the impacts of policy scenarios in a way that was sensitive to national and regional sustainability priorities, a key requirement of the tools set by the policy makers. 
Phase 1 involved the use of semi-structured interviews with individual stakeholders in order to define a number of policy scenarios representing possible national interpretations of the European Union policy, and it was informed by knowledge of specific sustainability problems (driver). This involved policy makers operating at a national level and responding to European Union policy directives and targets. A second round of interviews with regional stakeholders focused on the land-use changes (pressure) that were driven by the policy change.

In Phase 2, all the stakeholders involved in Phase 1 were brought together to participate in an sustainability impact assessment workshop. During the workshop, stakeholders carried out an analysis of sustainability criteria and an assessment of the changes in the corresponding social, environmental, and economic indicators that would result from implementing the proposed policy scenarios (state). This was followed by an analysis of the sustainability limits associated with each indicator, which were set by the stakeholders based on their knowledge of the current status of economic, social, and environmental resources. New indicator values could then be compared with sustainability limits (impact). Finally, sustainability criteria were reassessed to elicit stakeholder preferences for the scenarios (Morris et al. 2011).

The FoPIA is a microlevel tool used to generate results that may be specific to a defined geographic, socioeconomic, and environmental context. As such, analytical components, such as indicators, response functions, and limits are not predefined, but become the subject of discursive analysis during each phase of stakeholder engagement. For each policy case, detailed questions lead the participants through the steps of an impact assessment. General applicability to land-use related assessments has been purposefully designed into the FoPIA in the form of a number of consistently applied analytical mechanisms and procedures, such as the derivation and analysis of sustainability criteria and indicators, application of the land-use function concept (PerezSoba et al. 2008), and the analysis of sustainability impacts and limits. The approach has been adapted also to specific land-use cases in China (Zhen et al. 2009) and Indonesia (König et al. 2010).

\section{RESULTS}

\section{Case Study 1: Common Agricultural Policy financial reform scenario applied to the area of the European Union, and employing a modeling approach combined with a comprehensive indicator analysis}

\section{Land-use change}

Complete discontinuation of both agricultural market support and direct farm income support has two major effects on land use. Firstly, agricultural land decreases by only $2.5 \%$ in Europe in total, and secondly, within the agricultural land, arable land is substituted by grassland. A third important result was that land-use changes differed substantially across European regions. For example, a drop of agricultural land by more than $3 \%$ in response to the Common Agricultural Policy reform scenario was simulated for only 93 out of the 571 European regions (Fig. 3). Generally, reduction of agricultural land is due to abandonment of grassland in marginal regions while in other, more productive regions there is an increase in grassland at the expense of field crops (Fig. 3 and Fig. 4). These spatial shifts in grassland area can be attributed to the location of arable land. Arable land mostly occupies good agricultural soils, which are often better than the soils occupied by grassland. When the arable area shrinks, the soils become available to grassland, hence the migration of grassland to the former cropland. But increased grassland at these locations triggers abandonment of mostly extensively managed grassland areas on hill slopes and mountainous areas which have rather unfavorable conditions for intensive agricultural practices.

The only locations to be completely abandoned are marginal areas, i.e., those either poorly accessible or with limiting soil and climate conditions. In general, these are heterogeneous landscapes with a mosaic of grassland, arable land, and patches of natural vegetation with a high value for agrobiodiversity and cultural heritage. Land abandonment in these regions results in regrowth of natural vegetation, leading to a more homogeneous landscape which would eventually become dominated by larger, continuous areas of forest (MacDonald et al. 2000, Verburg and Overmars 2009), with negative implications for overall agrobiodiversity. 
Fig. 3. Common Agricultural Policy financial reform scenario: 100\% cut of Common Agricultural Policy first pillar measures (market support and direct income support), and re-investment of savings in research and development. The map outlines the impacts on the area covered by arable land in terms of absolute changes of the area share of arable land compared to the baseline on NUTS-X level in 2025.

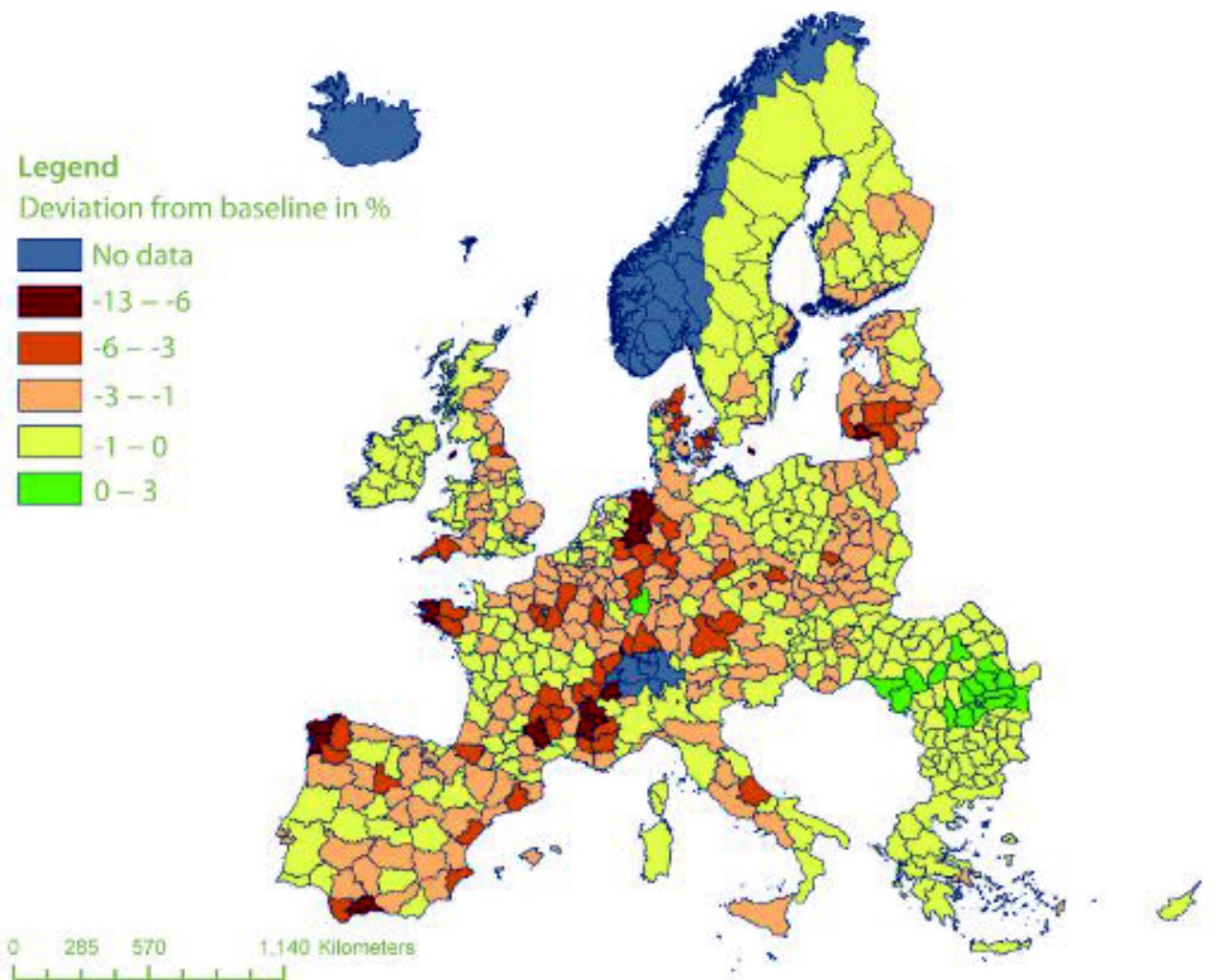

The land-use patterns of the highly productive agricultural regions are less sensitive to changes in the Common Agricultural Policy: they would remain predominantly agricultural areas. Urbanization is also not affected by this policy case. The baseline scenario and the Common Agricultural Policy scenario show no difference in area shares covered by urban land use (not shown here). Forest area is expected to increase by 0 to $4 \%$ in the Common Agricultural Policy reform scenario, with the highest increases in the least favoured areas (Bakker and Verburg 2009).

\section{Indicator results and sustainability impacts}

A small change in agricultural land cover does not mean that other aspects of agriculture (e.g., farm income) will not be affected. Compared to the baseline scenario (no change in policy), a complete cut of market-based and farm-support expenditures within the Common Agricultural Policy and redirection of the budget to research and development expenditures leads to a fall of $32 \%$ in farm income, a fall in agricultural prices of $9 \%$ on average, and an average fall in food prices of $1.3 \%$. This is accompanied by an overall increase in GDP and household consumption of $2.6 \%$ and $2.3 \%$ respectively (Fig. 5). The comparison of alternative budget spending shows that research and development re-investment can achieve more lasting and more widespread beneficial effects over sectors and social groups (Jansson et al. 2008b).

Reducing Common Agricultural Policy support will have positive effects on the total employment and on the economy as a whole but will be 
Fig. 4. Common Agricultural Policy financial reform scenario: 100\% cut of Common Agricultural Policy first pillar measures (market support and direct income support), and re-investment of savings in research and development. The map shows the impacts of the policy on grassland area in terms of absolute changes of the area share of grassland compared to the baseline on NUTS-X level in 2025.

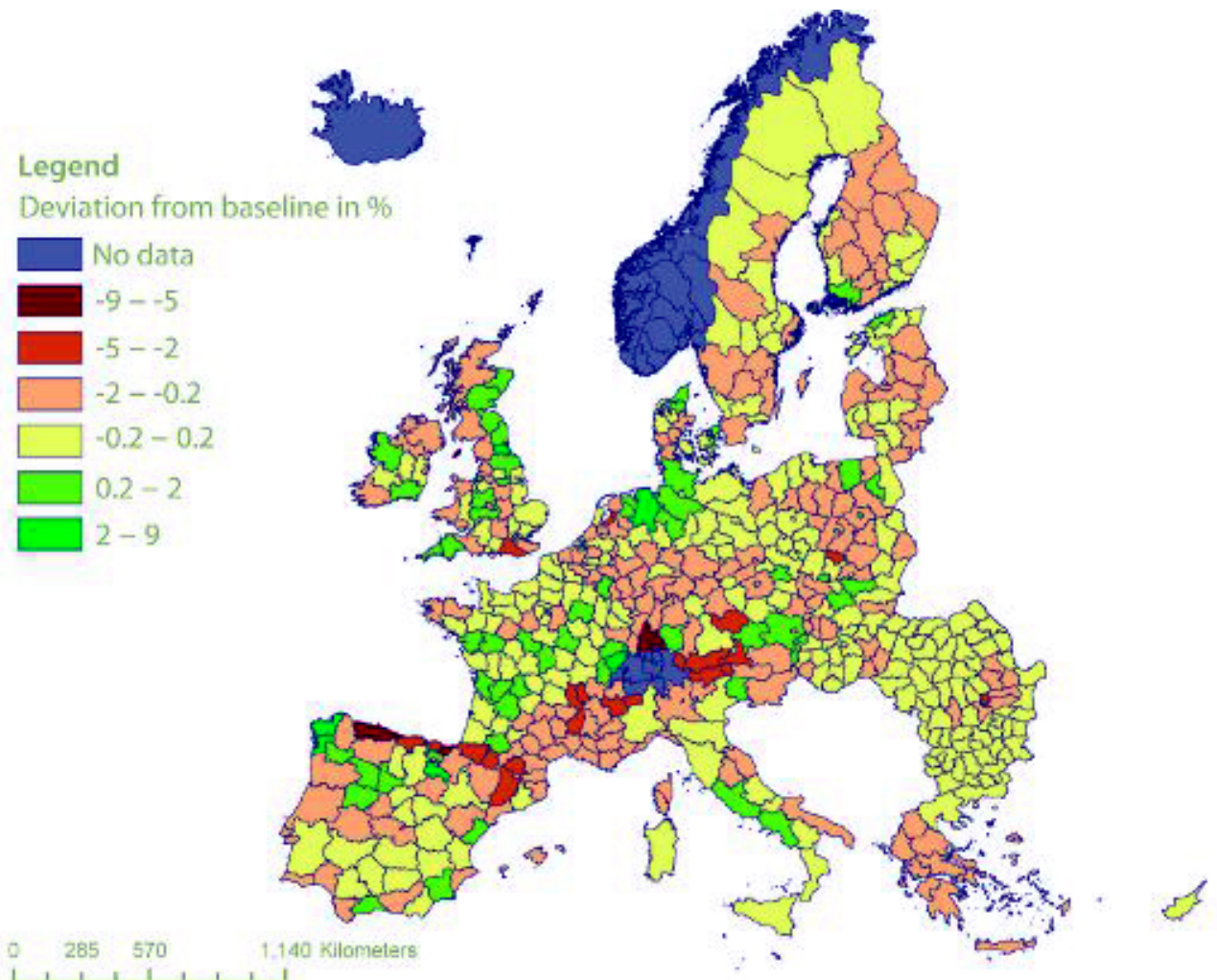

disadvantageous to the agricultural sector. Compared to the baseline scenario (situation in 2025 with no policy change), there would be a negative impact on employment in the agricultural sector with a fall of between 1 to $8 \%$ across European regions (Fig. 6). This can be interpreted as a simple acceleration of an already ongoing trend of structural change in agriculture, which has been held in check by the Common Agricultural Policy since 1992 and the economic restructuring of Commission of the European Communities. This is also manifested in the result for the baseline scenario for which a decline of agricultural employment of $9 \%$ is predicted on average when compared to the situation in the year 2000 .

Foreseen impacts on agricultural employment (calculated at a national level) are not uniform across the European Union member states but are predicted to be more pronounced in countries that benefit most from Common Agricultural Policy support and where structural changes in the agricultural market have been decelerated through policy regulations in the past. In general, countries with high agricultural employment may suffer from the decrease in agriculture more than they benefit from overall economic growth. The most pronounced impacts on agricultural employment are predicted for the Czech Republic and Estonia. In these cases, high shares of agricultural employment coincide with unfavorable natural production conditions and institutional settings that hamper structural change (Baum et al. 2007, Diehl et al. 2009).

With regard to the environmental impacts (Table 1), the projections show an overall improvement of the environmental state regarding the decrease of 
Fig. 5. Common Agricultural Policy financial reform scenario: 100\% cut of Common Agricultural Policy first pillar measures (market support and direct income support), and re-investment of savings in research and development. Simulated comparison of effects of tax rebate (TR) on GDP compared to reinvestment in research and development (R\&D).

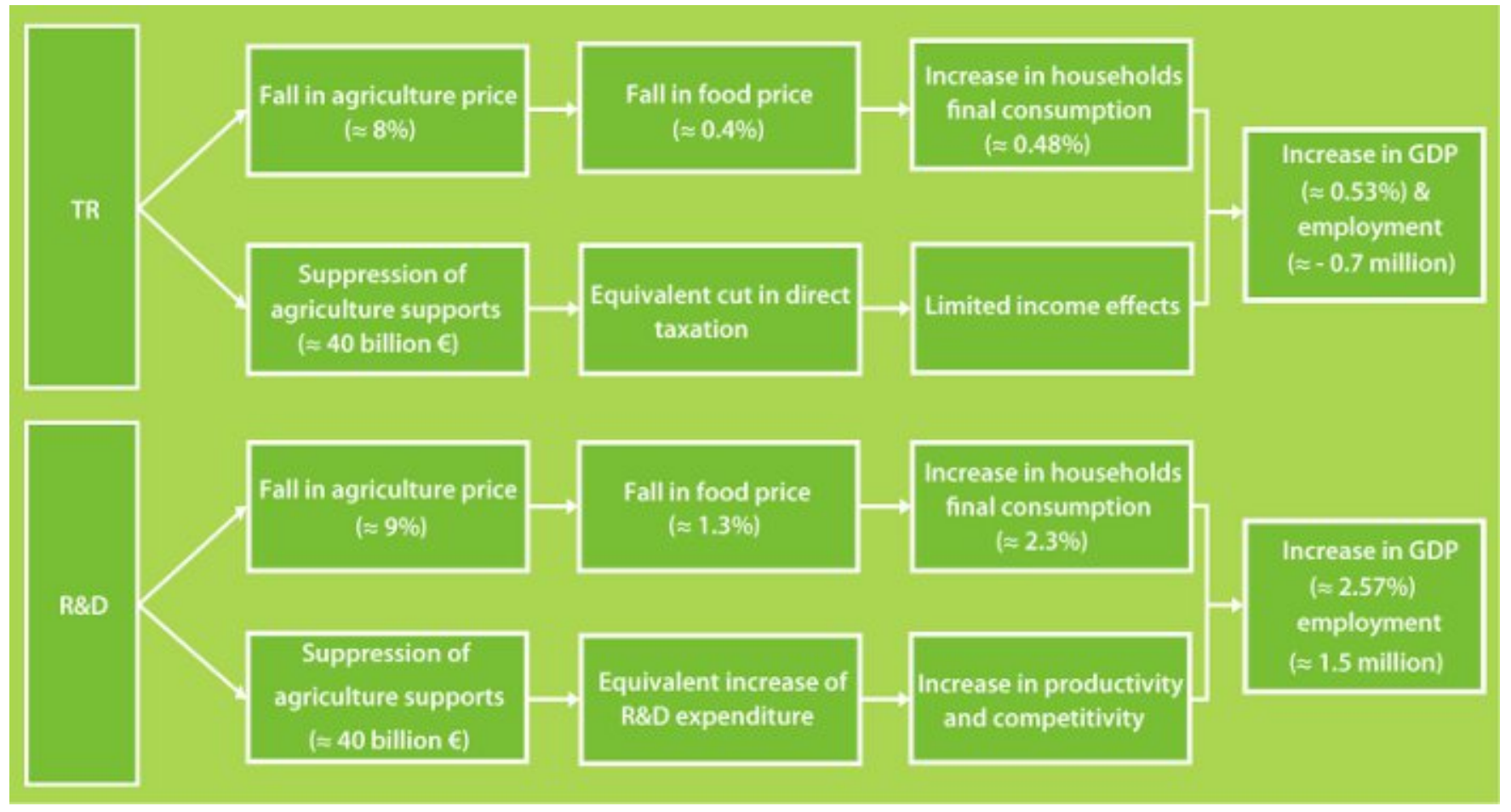

nitrogen and phosphorus surplus, ammonia emissions $\left(\mathrm{NH}_{3}\right)$, wind erosion, and habitat eutrophication, and regarding the increase in carbon sequestration and spatial cohesion (the latter being a biodiversity indicator). As an example of a positive effect, we analyzed the effects of financial reform on carbon sequestration in biomass, soil, and dead organic matter. The indicator was based on the approach developed for the DYNA-CLUE model by Schulp et al. (2008), but was extended by including direct effects of forest management on carbon sequestration in forest biomass, soil, and dead organic matter as projected by EFISCEN.

An increase in the demand for wood explains a net loss of carbon compared to the reference scenario in Finland, Romania, and Sweden. However, increasing carbon accumulation in some areas, resulting from agricultural abandonment, (natural) forest expansion, and reduced deforestation, compensates for this in other countries (Fig. 7). Overall, as a result of financial reforms, in 2025 there is a net gain of about $3575 \mathrm{Gg}$ of carbon in the sequestration of carbon in biomass, soil, and dead organic matter.

Some indicators reveal negative effects such as increases in pesticide use and in forest fire risk. Other indicators, such as standing deadwood, farmland birds, soil sealing, and emissions of greenhouse gases (e.g., nitrous oxide (N20) and methane (CH4)) do not show a consistent effect, some regions do improve, others worsen, or some regions are not affected at all. There is often a strong regional dimension to the pattern of change. In the case of phosphorus surplus (figure not shown), eastern European countries such as Romania and Bulgaria improve, while in parts of France, Spain, and Scandinavia phosphorus surplus increases dramatically. Regional variations in nutrient 
Fig. 6. Common Agricultural Policy financial reform scenario: 100\% cut of Common Agricultural Policy first pillar measures (market support and direct income support), and a re-investment of savings in research and development. The map shows the impacts on the number of employed persons in the agricultural sector in terms of the deviation from the baseline scenario for the year 2025 .

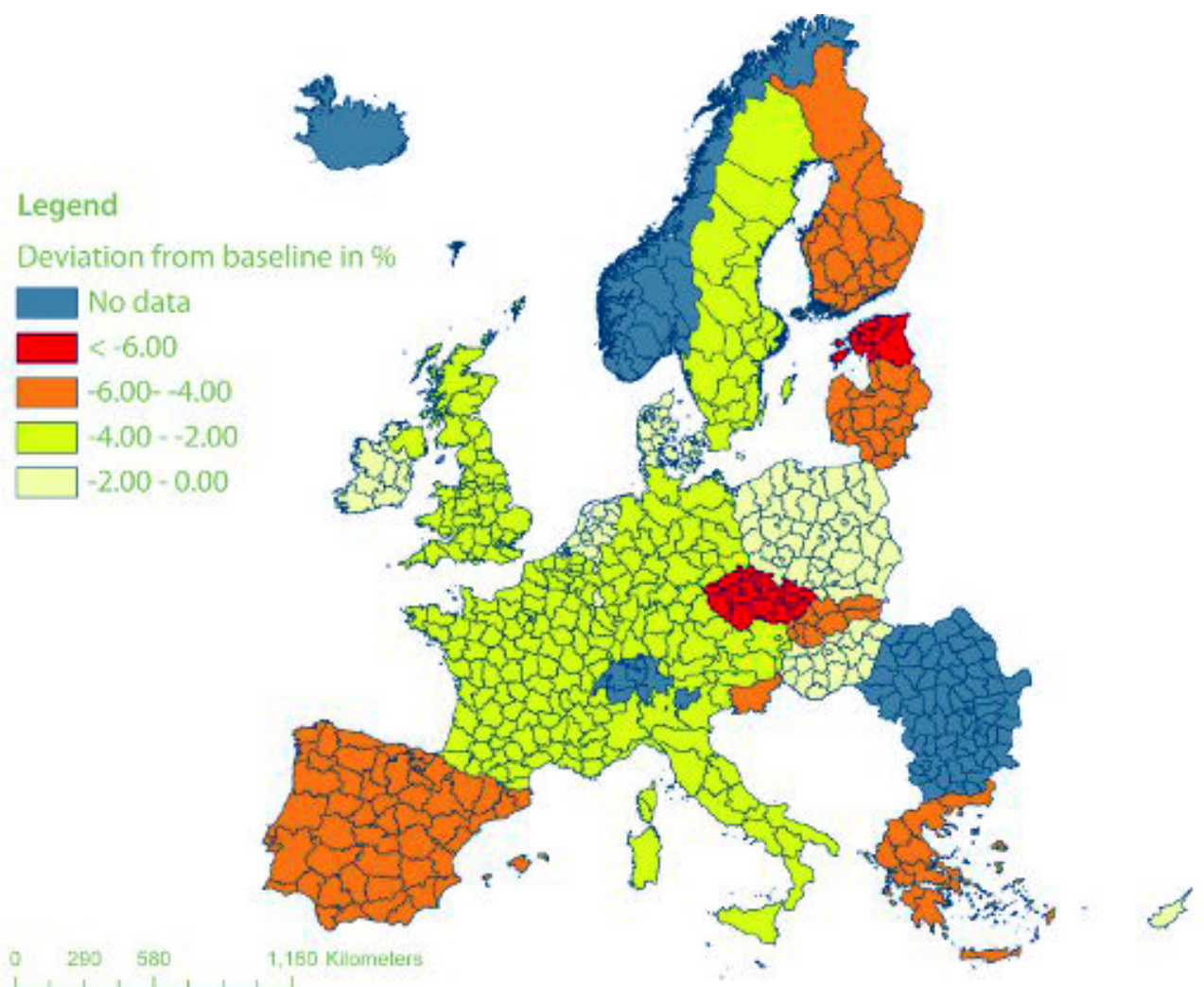

pressure depend mainly, on the one hand, on the interactions (simulated in the CAPRI model) between regional production characteristics such as animal husbandry (ruminants, pigs, poultry) and feeding systems (grazing, compound feed), and, on the other hand, the level of Common Agricultural Policy support coupled to animal production in the baseline (e.g., slaughter and suckler cow premia). Detailed results about specific indicators are documented by Bakker and Verburg (2009) for land-use changes, by Scholefield et al. (2009) for farmland birds, by Verkerk et al. (2009) for forest deadwood, by Renetzeder et al. (2009) for landscape patterns, by Podmanicky et al. (2009) for soil quality, by Jones et al. (2009) for nitrogen loads, and by Jansson et al. (2009) for nutrient pressures.

\section{Impact valuation}

The display of the calculations of the manifold indicator outcomes by way of applying the land-use functions allows an assessment at a regional level. In this study, assessments have been obtained through expert judgements employing specific regional expertise. This was done to re-inforce the validity of assessment results for the regional level. The results suggest that regions, which for historical reasons do not depend so much on market support or that specialize in less subsidized intensive agriculture, experience little effect from the Common Agricultural Policy scenario. This means that, considering the total of European agricultural production, no harmful impact on agricultural production is expected. Productivity will even 
Table 1. Common Agricultural Policy financial reform scenario: 100\% cut of Common Agricultural Policy first pillar measures (market support and direct income support); and re-investment of savings in research and development. Summary of the impacts for environmental indicators in Europe.

\begin{tabular}{lll}
\hline \hline Impact issues & Indicators & Effect of Policy \\
\hline Air quality & Ammonia emission from agriculture & Decrease \\
& Nitrogen dioxide emissions & No effect \\
Water quality and resources & Nitrogen surplus & Decrease \\
& Phosphorus surplus & Decrease \\
& Water retention capacity of the soil & No effect \\
Soil quality and resources & Soil sealing & Mixed effect \\
& Wind erosion & Decrease \\
Climate & Methane and nitrous oxide emission & Mixed effect \\
& Carbon sequestration & Increase \\
Biodiversity and landscapes & Terrestrial habitat eutrophication & Decrease \\
& Farmland birds, population trends & Mixed effect \\
& Deadwood & Mixed effect \\
& Spatial cohesion & Increase \\
\hline
\end{tabular}

increase at regional levels because of technological development.

In general it can be said that the more a country benefited from the Common Agricultural Policy, the more it is sensitive to the reform in terms of production decreases. This is significant for Spain and for some of the eastern European Union countries such as Hungary, Portugal, Romania, and Poland, and especially for regions consisting of mainly rural and remote areas with few cities. Calculations made for Jaén, a province of southern Spain and one of the largest producers of olive oil in the world, show that the impact of the Common Agricultural Policy reform will result in a decrease of land-based production (agriculture) and a slight decrease in the provision of work (Fig. 8). The heterogeneity of the landscape, and thus the cultural and aesthetic value, are predicted to increase with the abandonment of olive oil-focused agricultural production in this region (Perez-Soba et al. 2009).

\section{Case Study 2: bioenergy policy scenario applied to a postindustrial region in Silesia (Poland), and employing a participatory approach}

\section{Land-use change}

Silesia, a significant coal mining region of Poland, was identified as a case study suited to the assessment of bioenergy policy impacts. Any 
Fig. 7. Common Agricultural Policy financial reform scenario: 100\% cut of Common Agricultural Policy first pillar measures (market support and direct income support), and re-investment of savings in research and development. The map shows impacts on carbon sequestration $\left(\mathrm{Mg} \mathrm{C} \mathrm{km}^{-2}\right)$, and proportional changes with respect to the reference scenario for the year 2025.

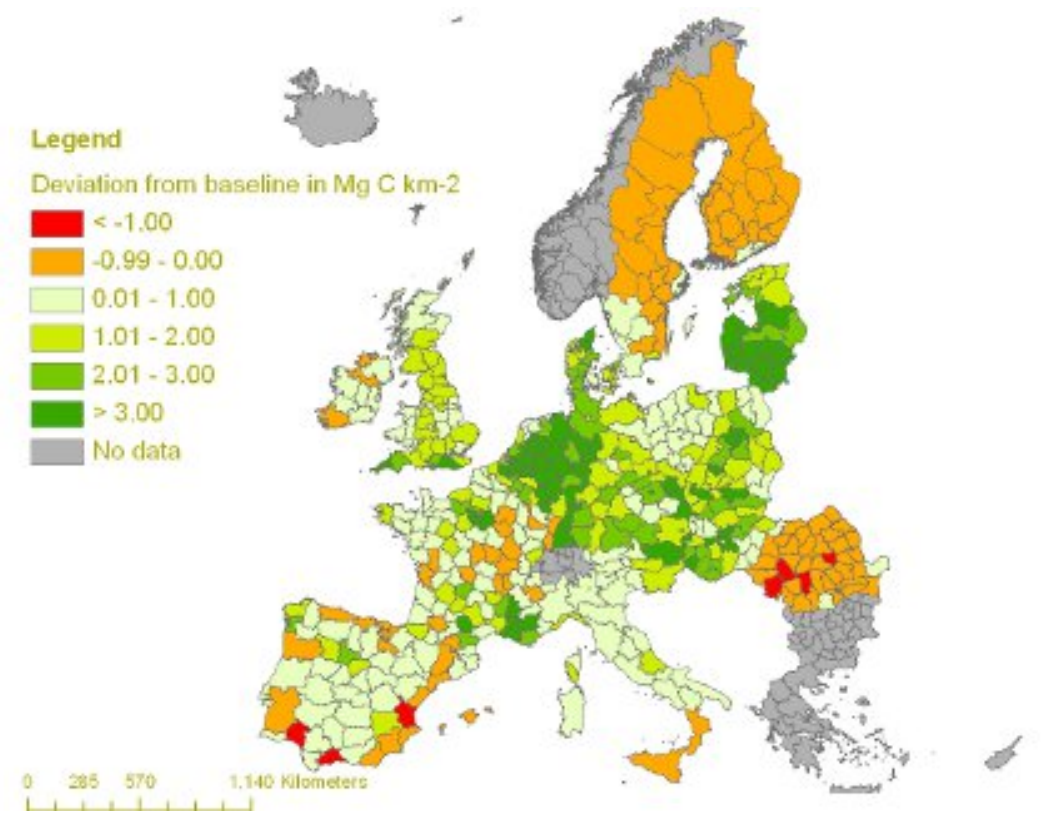

changes in energy sector policies would have significant consequences for sustainable development in the region, making it an interesting test case for ex ante impact assessment.

To identify the link between policy-change and land-use change, stakeholders formulated policy change scenarios for the year 2025 within the context of cross-sectoral development and land-use considerations. Three scenarios were developed: a baseline scenario with no changes to current policies (Scenario 1-low promotion of bioenergy); an increase in bioenergy cropping area to meet 2008 obligatory targets of the European Union (Scenario 2 - medium promotion of bioenergy); and intensive development of the bioenergy sector, with a substantial increase in the land area share dedicated to bioenergy crop production and supported by an incentive system (Scenario 3-high promotion of bioenergy).

Stakeholders expected that, under Scenario 1, the area dedicated to the bioenergy crops would not change substantially in the region. Rather, this scenario simply reflects an extrapolation of past trends in bioenergy development. Under Scenario 2 , however, there was agreement that bioenergy cropping area (used both for electrical energy and biofuel production) would increase to meet the current obligatory targets. Under Scenario 3, the area of bioenergy crops and "biofuel" crops would increase significantly as a result of increased subsidies and/or higher quantitative targets, thus causing significant land-use changes.

\section{Indicator results}

Indicators were identified and allocated to each one of the land-use functions in order to define precisely how changes in land-use functions would be measured in Silesia (Table 2). To enable the subsequent analysis and scoring, the indicators were expressed as impact assessment questions. This process of indicator definition then provided the basis for all following assessments of the impacts of the land-use changes induced by the policy scenarios. 
Fig. 8. Common Agricultural Policy financial reform scenario: 100\% cut of Common Agricultural Policy first pillar measures (market support and direct income support), and re-investment of savings in research and development. The image shows impacts on land-use functions in Jaén, a province in southern Spain, and the land-use function scores for baseline and Common Agricultural Policy reform scenarios in 2025.

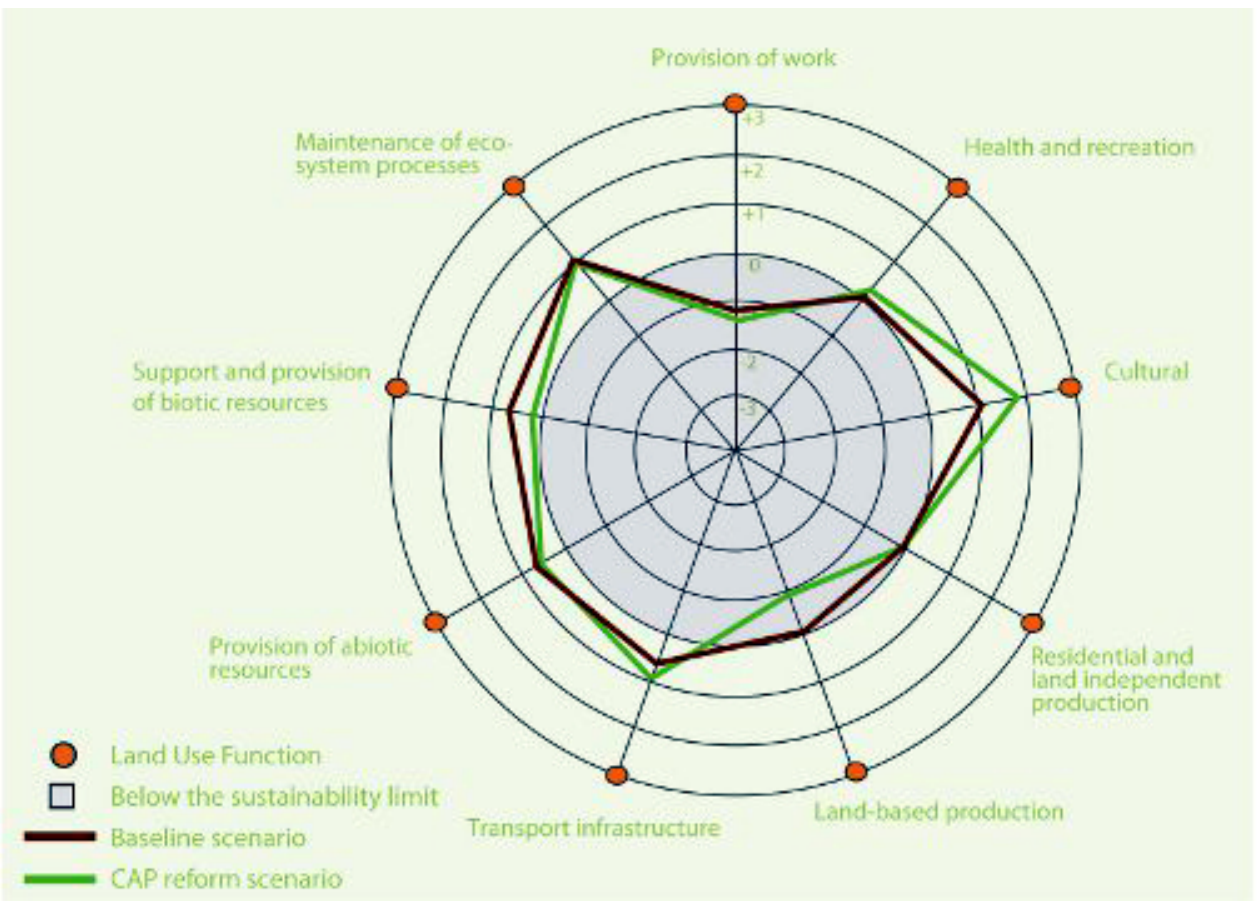

\section{Impact valuation}

Scenario 2 represented currently existing policy instruments and assumed a moderate increase of bioenergy cropping area. Compared to the baseline (low promotion Scenario 1) this scenario would have a predominantly positive impact on land-use functions (Fig. 9). The exception was biodiversity, where the stakeholder group expected a slight negative impact on species population numbers as a result of changes in cropping structure; more land allocated to bioenergy crop production was estimated to lead to a simplification of the crop rotation, with reduced diversity of crops cultivated. The continuation of current policies would also have a positive impact on two out of three social functions of land use, namely employment and public health.

In the spider diagram of Fig. 9, the zero line represents the minimum sustainability standards for each land-use function set by the stakeholder group. Results indicate that sustainability standards will be reached for all functions, with the exception of the cultural function (landscape aesthetics and quality). This outcome is perhaps more of a reflection that very high sustainability standards were set by the group, implying that all dimensions of sustainability need substantial improvement in Silesia.

The largest differences between impacts can be observed under the high promotion Scenario 3. This scenario represents intensive production and uncontrolled expansion of the bioenergy cropping area. The results show that this development would greatly increase employment and production in agriculture, but at the expense of negative impacts on biodiversity and the efficiency of the road network. The latter can be explained by the current poor state of the road network in the region, which would only be exacerbated by the increase in traffic 
Table 2. Land-use functions and indicators used by stakeholders for impact assessment of scenarios and sustainability limits.

\begin{tabular}{llll}
\hline \hline Land-use function & Criteria & Indicator \\
\hline SOC-1 & Cultural & Cultural and natural heritage & Visual attractiveness \\
SOC-2 & Health and recreation & Health of population & Life expectancy \\
SOC-3 & Provision of work & Employment generation & Employment \\
ECO-1 & Residential and non-land-based & Industry and urbanization & Value added in industry \\
ECO-2 & industries and services & development & Value added in agricultural \\
ECO-3 & Infrastructure and mobility & Agricultural production & sector \\
ENV-1 & Provision of abiotic resources & Water retention & Transferability \\
ENV-2 & Provision of biotic resources & Biodiversity & Amount of retained water \\
ENV-3 & Maintenance of ecosystem processes & Environmental quality & Species number \\
\hline
\end{tabular}

volumes associated with intensified production and processing of biomass. A comparison of the impacts on social functions reveals that intensive bioenergy promotion can have a beneficial impact on the health and recreation function and the provision of work function. According to stakeholder opinion this is due to an expected reduction of emissions related to coal burning, which will be partially replaced by biofuels, thus alleviating the exposure to pollution and diminishing related health risk. Expected provision of work is associated with a growth of the market of biofuel products to be delivered by new businesses which would be established in rural areas. The predicted negative cultural impacts can be explained by concerns that bioenergy monocropping would degrade the visual attractiveness of the landscape and its traditional mosaic pattern. Losses of functionality in terms of provision of biotic resources and provision of habitat are expected, in return for significant gains in the economic land-use functions. As with the other scenarios, sustainability standards are not met under Scenario 3, except in terms of the land-based production function (provision of land for production activities that do not result in irreversible change). It is worth emphasizing that a slightly or moderately positive impact on a given land-use function is often assessed by stakeholders as below sustainability standards. In other words the stakeholders' expectations for policies are set very high and the analyzed scenarios were valued as an improvement, albeit not sufficient to meet their standards for sustainable land-use functions.

A comparison of the impacts of the baseline scenarios reveals that no change in policy from the present situation is predicted to have either a slightly positive or a neutral effect on the social and economic functions of land use. Perhaps unsurprisingly, the most significant gains in functionality are predicted to be in the provision of work function and in the residential and land independent production function. Negative impacts are predicted for the provision of habitat function.

\section{DISCUSSION}

It is fair to say that no methodological framework for ex ante impact assessment will ever manage to comprehensively capture the complex relationships between changes in policy, changes in land use, and the resulting changes in social, economic, and environmental systems. Furthermore, no approach 
Fig. 9. Silesia, Poland, bioenergy promotion policy scenario: impact on land-use functions. The diagram shows impact assessment scores for land-use functions under three policy scenarios in 2025, as derived through a stakeholder participatory process.

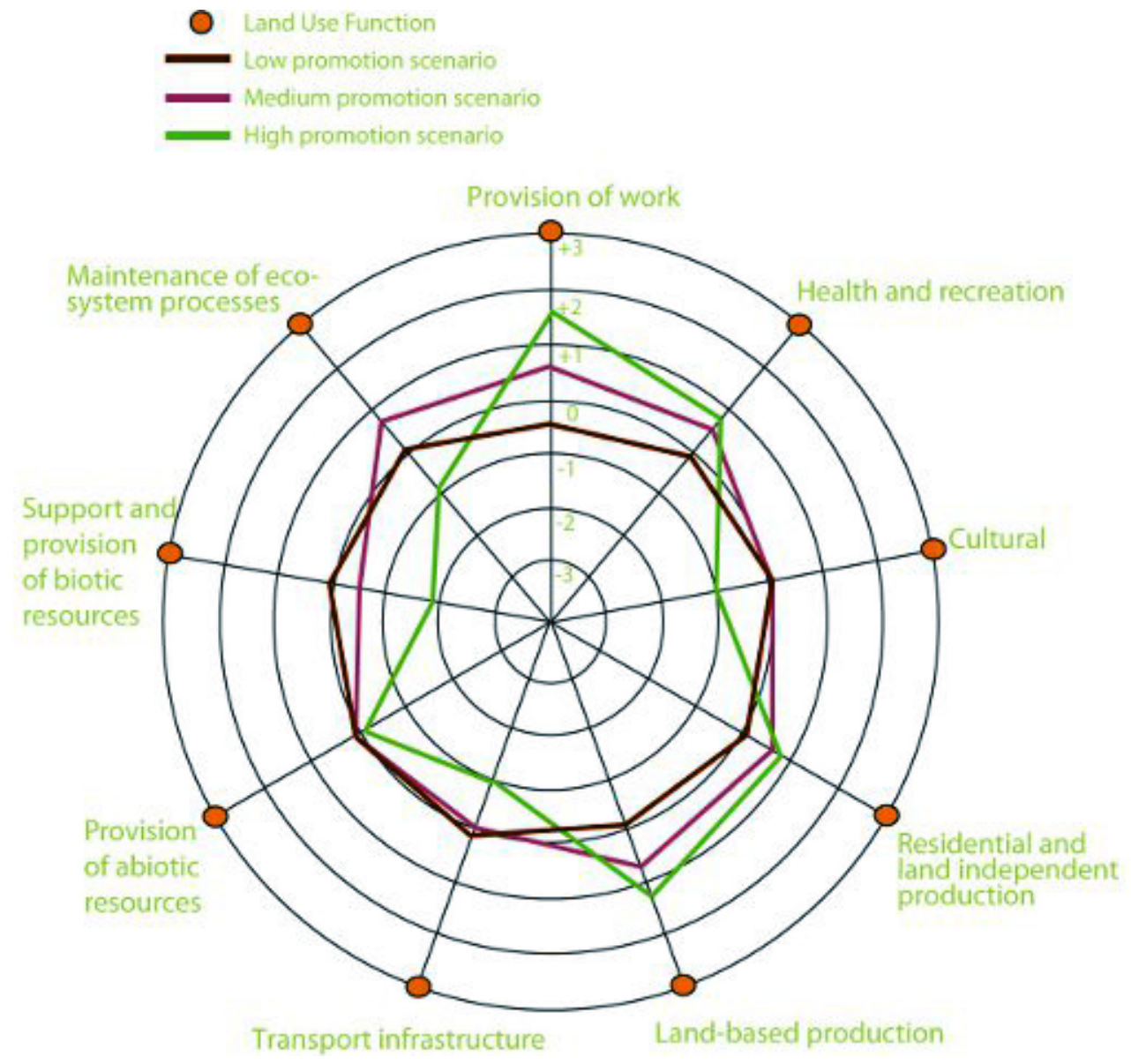

will ever be able to capture and reflect comprehensively the possible range of values and judgments that could be implicated in the decisions that flow from the impact assessment process. Any tool, mechanism, or methodological framework for impact assessment must confront the tension between the enormous complexity of the systems and subsystems under analysis and the necessary simplifications that need to be imposed to make the analysis possible (Mcintosh et al., 2008).

A key advantage of using the system of linked models (Case Study 1) is that it makes possible the simultaneous consideration of all relevant sectors of the economy (within NEMESIS) without abstaining from a great level of detail for sectors of particular interest, i.e., agriculture and forestry (Uthes et al. 2010). Neither model used by itself could have obtained the rich set of results. Furthermore, by evaluating the results of simulation experiments with the whole system versus results obtained from the same models without linkages, a measure may be obtained to the extent of which the linkages actually matter substantially to the outcomes. The results of such a comparison are clear. A policy shock introduced in one sector, for example agriculture, does indeed also significantly affect other sectors, and the effects on the sector where the shock was introduced also clearly depend on the interactions with other sectors. 
Other advantages lie in the incontestable character of the results. Based on neutral, existing data with a fixed set of settings and regions, an absolute comparability and reproducibility throughout the Europe Union can be maintained.

To overcome the disadvantages related to the complexity of linked comprehensive models, the metamodel approach, based on a range of precooked scenario results, was established in Case Study 1 (Sieber et al. 2008). This allowed a rapid performance of the metamodel, thus enhancing the usability of the tool. Still it did not help to overcome the kind of black-box character that such comprehensive models appear to have to users with no extensive background in modeling. Another severe limitation in policy relevance is the programming of fixed settings. A new policy case would always require the adjustment of the model suite, which makes it inflexible in the face of timely decisions. Albeit comprising uncountable potential calculations and results, the metamodel itself has no model-based valuation system. The application of the metamodel makes sense only when combined with expert interpretations. Although a participatory valuation was included in the testing of the approach, more knowledge on the topic of dealing with the complexity of the results would be necessary. The aggregation of the manifold indicator results to the nine land-use functions involved extensive expert judgement and required extensive interdisciplinary cooperation. The outcome was a translation of science-based results into a real-world context, which allowed for a comparative valuation of the simulated impacts in the context of sustainable development and which considerably enhanced the usability for the policy context.

FoPIA, the Framework for Participatory Impact Assessment, as applied in Case Study 2, followed a transdisciplinary approach and involved national, regional, and local stakeholders in assessments of land-use policy impacts. Differences in approach between the two tools were not merely accidental, but were the result of a considered process of FoPIA design. The intention was to produce an alternative methodological framework for sustainability impact assessment that will enable the constructive problematization of its model-based cousin. The tool is process oriented in that it supports discussion among stakeholders, key players, and decision makers, and provides a discursive space for the exchange of knowledge. It is also results oriented, because it aims to produce knowledge about the potential application and consequences of proposed policy changes.

It was realized that the regional impacts of policies would depend upon national interpretations of European policies (Morris et al. 2008). The subsequent decision to build into the FoPIA the capacity to define regionally plausible policy scenarios as the starting point for the subsequent analytical process proved to be well founded. There was a high level of interest in plausible scenario development displayed by all the stakeholder groups, and by the significant degree of variation between the scenarios derived in different regions. The need to define regionally plausible policy scenarios for an accurate sustainability impact assessment at the regional level should therefore be recognized as an important research finding.

The development of the participatory approach was motivated by the perceived instrumental potential inherent in a research approach that can harness expertise and knowledge of specific contexts. In particular, it was felt that the knowledge of local stakeholders could be applied to predictions of complex policy impacts and, crucially, the relationships between impacts, to produce assessments that would provide a useful complement to model-based approaches.

Differences between conceptions of policy change at the political center and the political periphery should not be taken as evidence of a flaw in the logical framework. Rather, they are indicative and suggestive of the additional analytical capacities that would be needed to enhance the regional accuracy and sensitivity of an impact assessment process that follows the selection of policy scenarios. Here it is possible to see how the modeling approach and the participatory approach might be used in combination, with the model application being used as an initial "quick-scan" tool to highlight particular problem areas that warrant further and more detailed analyses of impacts. This could then trigger stakeholder involvement to conduct a regional impact assessment that can add to the analytical scope by identifying the limitations of a mechanistic, datadriven approach and by indicating where additional capabilities need to be developed.

The development of the analytical framework for impact assessment (Helming et al. 2011a) and its 
implementation with a modeling approach and a participatory approach was accompanied by an iterative process of end-user consultations about the design and functionalities of the impact assessment tool. Three potential user groups, each with different requirements, have been identified: (1) the end users at the level of the European Commission as key contractors and decision makers, (2) the research institutes providing decision makers with direct information on model analysis, and (3) the numerous consultancies that are involved in impact assessment studies (Sieber et al. 2008). The first group will not likely use comprehensive tools themselves, i.e., neither data-driven quantitative nor participatory and qualitative tools. However, they will appreciate the value born by the robustness and reliability of studies that are based on scientifically justified, quality-approved tools (Thiel et al. 2009). This makes the tools interesting for the second and third group when being involved in studies in support of impact assessment. They take the role of brokers between the research and the policy community, and need an analytical framework for feeding science-based analytical elements into the impact assessment process. Here, hard technical concerns of modelling and analytical depths seem to be less of a problem compared to the challenge of capturing the full analytical cycle of impact assessment: starting with a problem analysis, defining scenarios, simulating impacts, and finally valuating impacts in the light of predefined targets (McIntosh et al. 2007). Transparency, sensitivity to the policy context, and user orientation are therefore important characteristics of any tools and analytical frameworks used in support of impact assessment (Helming et al. 2011a).

The analytical framework realized in both approaches facilitates a flow of analysis that is necessarily a considerable simplification of a complex system. In the case of the participatory approach, this simplification is borne not only out of a realistic appraisal of what is analytically possible, but also of what is socially possible. The fact that implementing the participatory approach in a region required the voluntary cooperation and participation of a number of people meant that the need for relative simplicity and efficiency became central design considerations. This necessary regime of simplification is inherent in the analytical framework and is a design element in both application examples. In particular, the use of the nine land-use functions and their required transformation of scientific analysis into the real work context provided the efficient structuring of the main analytical processes. That said, the generally positive feedback suggests that the stakeholders understood and accepted these mechanisms as necessary impositions.

\section{CONCLUSION}

The implementation of the analytical framework for impact assessment proved to be applicable with both methods, i.e., the quantitative modeling and the qualitative participatory approach. Analyzing the pros and cons of both approaches showed that they should be used complementarily rather than be seen as competing alternatives. In this regard, it is interesting to see how the modeling approach and the participatory approach might be used in combination, with the modeling being used as an initial "quick-scan" tool to highlight particular problem areas that warrant further and more detailed analyses of impacts, thereby triggering the application of stakeholder inclusive research to carry out an assessment at case study level.

Both tools are carefully structured around the DPSIR framework, with the intention of producing results that both complement and force critical engagement with the results and analytical scope of this automated tool. In this sense, the participatory approach proposes an additional level of integration to those outlined in the introduction (integration across sectors, and across the pillars of sustainability), the insights gained through a deliberative research approach involving stakeholders closely relates to and feeds into the insights gained through model-based analyses, thus offering the potential for integration across methodological and epistemological boundaries. The application of the land-use function concept in the impact valuation phase made this integration operational in translating the results of science-based analysis into a real world context that is comprehensible by those making policies, as well as by those affected by policies. This valuation of research outcomes from the perspective of the affected stakeholders was an attempt to close the gap between research-based analysis and research-based decision making. Here lies an innovative field of research for sustainable development that will continue to preoccupy researchers. 
Responses to this article can be read online at: http://www.ecologyandsociety.org/voll6/iss1/art29/ responses/

\section{Acknowledgments:}

The research for this article was executed as part of the SENSOR integrated project funded under the EU 6th Framework Programme for Research, Technological Development and Demonstration, Priority 1.1.6.3. Global Change and Ecosystems (European Commission, DG Research, contract $003874(G O C E))$. The authors would like to thank the European Commission for the financial support received, and the SENSOR consortium members for their kind collaboration and for the many fruitful discussions and debates that helped shape the thinking behind the paper. The authors also thank the two reviewers for their helpful comments for improving earlier versions of the paper.

\section{LITERATURE CITED}

Bach, H., M. Bakker, J. Farrington, Z. Drillet, B. Duray, P. Frederiksen, K. E. Gyuró, T. Henrichs, K. Jansson, T. S. Jensen, S. Jombach, L. Jones, B. Kaae, M. Lindner, A. Lopatka, N. Kohlheb, T. Kuhlman, S. Petit, M. L. Paracchini, L. K. Petersen, L. Reid, D. Rothman, P. Scholefield, N. Schulp, T. Stuczynski, M. van Eupen, P. Verburg, H. Verkerk, J. Vogt, F. P. Vinther, and C. Wilson. 2008. Indicators-methodology and descriptions. SENSOR Report Series 2008/7. Leibniz-Centre for Agricultural Landscape Research (ZALF), Müncheberg, Germany.

Bäcklund, A.-K. 2009. Impact assessment in the European Commission - a system with multiple objectives. Environmental Science and Policy 12 (8):1077-1087. doi: 10.1016/j.envsci.2009.04.003.

Bakker, M., and P. H. Verburg. 2009. Scenario based forecasts of land use and land management at $1 \mathrm{~km}^{2}$ grid and NUTS-X level, based on CLUES. SENSOR Report Series 2009/10, Leibniz-Centre for Agricultural Landscape Research (ZALF), Müncheberg, Germany.
Bastian, O., R. Krönert, and Z. Lipsky. 2006. Landscape diagnosis on different space and time scales - a challenge for landscape planning. Landscape Ecology 21:359-374.

Baum, S., H. Stange, and P. Weingarten. 2007. Employment in agriculture in the enlarged European Union. Geographische Rundschau, International Edition 3(2):4-13.

Brécard, D., A. Fougeyrollas, P. Le Mouel, L. Lemiale, and P. Zagame. 2006. Macro-economic consequences of European research policy: prospects of the Nemesis model in the year 2030. Research Policy 35(7):910-924

Britz, W., and P. Witzke. 2008. CAPRI model documentation 2008: version 2. Common Agricultural Policy Regionalised Impact Modelling System (CAPRI Modelling System), Institute for Food and Resource Economics, University of Bonn, Bonn, Germany. [Online] URL: http://www.capri-m odel.org/docs/capri documentation.pdf.

Busch, G. 2006. Future European agricultural landscapes-what can we learn from existing quantitative land use scenario studies? Agriculture, Ecosystems \& Environment 114:121-140.

Carpenter, S. R., E. M. Bennett, and G. D. Peterson. 2006. Editorial: special feature on scenarios for ecosystem services. Ecology and Society 11(2): 32. [Online] URL:http://www.ecologyandsociety.org/vol11/ iss $2 / \operatorname{art} 32 /$.

Commission of the European Communities. 2008. Proposal for a directive of the European Parliament and of the Council on the promotion of the use of energy from renewable sources (presented by the Commission). Brussels, 23.1.2008, COM(2008) 19 final, 2008/0016(COD). [Online] URL:http://ec.eu ropa.eu/energy/climate actions/doc/2008 res direc tive en.pdf.

Council of the European Union. 2006. Renewed EU sustainable development strategy, Brussels, 26 June 2006. 10917/06. [Online] URL:http://ec.europa.eu/ sustainable/docs/renewed eu sds en.pdf.

Diehl, K., B. König, K. Helming, and D. Wascher (editors). 2009.Toolsforimpact assessment: project summary, IP SENSOR. Leibniz-Centre for 
Agricultural Landscape Research (ZALF), Müncheberg, Germany.

European Commission. 2005. Impact assessment guidelines, 15 June 2005 with March 2005 update on procedural rules. SEC(2005) 791.

European Commission. 2009. Impact assessment guidelines, 15 January 2009. SEC(2009) 92. [Online] URL:http://ec.europa.eu/governance/impact/ commission guidelines/docs/iag 2009 en.pdf.

European Parliament. 2000. Lisbon European Council, 23 and 24 March 2000, presidency conclusions.[Online] URL:http://www.europarl.eur opa.eu/summits/lis1 en.htm.

Eurostat. 2010. NUTS-nomenclature of the territorial units for statistics. European Commission, Luxembourg, Belgium. [Online] URL:http://epp.eu rostat.ec.europa.eu/portal/page/portal/nuts nomenclature/ introduction

Ewert, F., M. K. van Ittersum, I. Bezlepkina, O. Therond, E. Andersen, H. Belhouchette, C. Bockstaller, F. Brouwer, T. Heckelei, S. Janssen, R. Knapen, M. Kuiper, K. Louhichi, J. A. Olsson, N. Turpin, J. Wery, J. E. Wien, and J. Wolf. 2009. A methodology for integrated assessment of policy impacts in agriculture. Environmental Science \& Policy 12(5):546-561. doi:10.1016/j.envsci.2009.02.005.

Håkan, W. 2008. R\&D expenditure and personnel. Statistics in Focus 91/2008. Eurostat, European Commission, Luxembourg, Belgium. [Online] URL: http://epp.eurostat.ec.europa.eu/cache/ ITY OFFPUB/KS-SF-08-091/EN/KS-SF-08-091-EN. PDF.

Helming, K., I. de la Flor, and K. Diehl. 2011a. Integrated approaches for ex-ante impact assessment tools - the example of land use. In A. von Raggamby and F. Rubik, editors. Sustainable development evaluation and policy-making. Edward Elgar, Cheltenham, Gloucestershire, UK, in press.

Helming, K., K. Diehl, H. Bach, O. Dilly, B. König, T. Kuhlmann, M. Perez-Soba, S. Sieber, P. Tabbush, K. Tscherning, D. Wascher, and $\mathrm{H}$. Wiggering. 2011b. Ex ante impact assessment of policies effecting land use, Part A: analytical framework. Ecology and Society 15(4): 27. [Online] URL: http://www.ecologyandsociety.org/vol16/iss1/ art27/.
Helming, K., P. Tabbush, and M. Perez-Soba (editors). 2008. Sustainability impact assessment of land use changes. Springer-Verlag, Berlin and Heidelberg, Germany.

Jansson, T. 2009. Protocols for integration of model and indicator outputs into SIAT. SENSOR Report Series 2009/5. Leibniz-Centre for Agricultural Landscape Research (ZALF), Müncheberg, Germany.

Jansson T., M. M. Bakker, B. Boitier, A. Fougeyrollas, J. Helming, H. van Meijl, and P.J. Verkerk. 2008a. Linking models for land use analysis: experiences from the SENSOR project. In Conference Proceedings of the XIIth Congress of the European Association of Agricultural Economists, Ghent, Belgium, August 26-29 2008. [Online] URL: http://ageconsearch.umn.edu/bitstre am/44169/2/570.pdf.

Jansson, T., M. Bakker, B. Hasler, J. Helming, B. Kaae, P. Lemouël, S. Neye, R. Ortiz, T. Sick Nielsen, D. Verhoog, and H. Verkerk. 2009. Baseline scenario storylines. SENSOR Report Series 2009/2. Leibniz-Centre for Agricultural Landscape Research (ZALF), Müncheberg, Germany.

Jansson, T., M. M. Bakker, P. Le Mouël, D. Schirmann-Duclos, D. Verhoog, and P. J. Verkerk. 2008 b. Dynamic impacts of a financial reform of the CAP on regional land use, income and overall growth. In Conference Proceedings of the XIIth Congress of the European Association of Agricultural Economists, Ghent, Belgium, August 26-29 2008. [Online] URL: http://ageconsearch.umn. edu/bitstream/43640/2/047.pdf.

Jones, M. L. M., D. Norris, J. Hall, and S. Petit. 2009. Developing an indicator-modelling approach to forecast changes in nitrogen critical load exceedance across Europe arising from agricultural reform. Ecological Indicators 11(1):16-26. doi:10.1016/ j.ecolind.2009.06.005.

König, H., J. Schuler, U. Suarma, D. McNeill, J. Imbernon, F. Damayanti, S. A. Dalimunthe, S. Uthers, J. Sartohadi , K. Helming, and J. Morris. 2010. Assessing the impact of land use policy on urban-rural sustainability using the FoPIA approach in Yogyakarta, Indonesia. Sustainability 2 (7):1991-2009. 
Kristensen, P., P. Frederiksen, V. Briquel, and M. L. Paracchini. 2009. SENSOR indicator framework - guidelines for selection and aggregation. SENSOR Report Series 2009/3. Leibniz-Centre for Agricultural Landscape Research (ZALF), Müncheberg, Germany.

Kuhlman, T. 2008. Scenarios: driving forces and policies. Pages 131-157 in K. Helming, P. Tabbush, and M. Perez-Soba, editors. Sustainability impact assessment of land use changes. Springer-Verlag, Berlin and Heidelberg, Germany.

MacDonald, D., J. R. Crabtree, G. Wiesinger, T. Dax, N. Stamou, P. Fleury, J. Gutierrez Lazpita, and A. Gibon. 2000. Agricultural abandonment in mountain areas of Europe: environmental consequences and policy response. Journal of Environmental Management 59:47-69.

McIntosh, B. S., C. Giuppponi, C. Smith, A. Voinov, H. Assaf, N. Crossman, N. Gaber, J. Groot, D. Haase, D. Hepting, R. Kolkman, K. Matthews, M. Monticino, J. Mysiak, N. Quinn, H. Scholten, and S. Sieber. 2008. Bridging the gaps between design and use: developing tools to support management and policy. Developments in Integrated Environmental Assessment 3:33-48.

McIntosh, B. S., R. A. F. Seaton, and P. Jeffrey. 2007. Tools to think with? Towards understanding the use of computer-based support tools in policy relevant research. Environmental Modelling and Software 22:640-648.

Millennium Ecosystem Assessment. 2003. Ecosystems and human well-being: a frameworkfor assessment. Island Press, Washington, D.C., USA.

Morris, J., M. Camilleri, and S. Moncada. 2008. Key sustainability issues in European sensitive areasa participatory approach. Pages 451-470 in K. Helming, P. Tabbush, and M. Perez-Soba, editors. Sustainability impact assessment of land use changes. Springer-Verlag, Berlin and Heidelberg, Germany.

Morris, J., V. Tassone, R. de Groot, M. Camilleri, and S. Moncada. 2011. A framework for participatory impact assessment: involving stakeholders in European policy making, a case study of land use change in Malta . Ecology and Society 16(1): 12. [Online] URL: http://www.ecologyandsociety.org/ vol16/iss 1/art12/.
Paracchini, M. L., C. Pacini, M. L. M. Jones, and M. Pérez-Soba. 2009. An aggregation framework to link indicators associated with multifunctional land use to the stakeholder evaluation of policy options. Ecological Indicators 11(1):71-80. doi:10.1016/j.ecolind.2009.04.006.

Pérez-Soba, M., M. Danes, L. Jones, S. Petit, N. Bertrand, V. Briquel, M. L. Paracchini, P. Kenderessy, F. P. Vinther, B. Hasler, C. Pacini, C. Contini, L. Omodei Zorini, Z. Imrichova, J. Farrington, D. Rothman, E. Konkoly, S. Jombach, and Z. Tatai. 2009. Framework and methodology for a regional sustainability assessment based on land use functions. SENSOR Report Series 2009/4. Leibniz-Centre for Agricultural Landscape Research (ZALF), Müncheberg, Germany.

Perez-Soba, M., S. Petit, L. Jones, N. Bertrand, V. Briquel, L. Omodei-Zorini, C. Contini, K. Helming, J. Farrington, M. Tinacci Mossello, D. Wascher, F. Kienast, and R. de Groot. 2008. Land use functions - a multifunctionality approach to assess the impact of land use change on land use sustainability. Pages 375-404 in K. Helming, P. Tabbush, and M. PerezSoba, editors. Sustainability impact assessment of land use changes. Springer-Verlag, Berlin and Heidelberg, Germany.

Plummer, M. L. 2009. Assessing benefit transfer for the valuation of ecosystem services. Frontiers in Ecology and Environment 7(1):38-45.

Podmanicky, L., K. Balazs, M. Belenyesi, C. S. Centeri, D. Kristof, and N. Kohlheb. 2009. Modelling soil quality changes in Europe. an impact assessment of land use change on soil quality in Europe. Ecological Indicators 11(1):4-15. doi:10.1016/ j.ecolind.2009.08.002.

Prins, A. G., B. Eickhout, M. Banse, H. Meijl, W. Rienks, and G. Woltjer. 2011. Global impacts of European agricultural and biofuel policies. Ecology and Society in press.

Renetzeder, C. S. Schindler, J. Peterseil, M. A. Prinz, S. Mucher, and T. Wrbka. 2009. Can we measure ecological sustainability? Landscape pattern as an indicator for naturalness and land use intensity at regional, national and European level. Ecological Indicators 10(1):39-48. doi:10.1016/j. ecolind.2009.03.017 
Renetzeder, C., M. van Eupen, C. A. Mücher, and T. Wrbka. 2008. Clustering Europe: a spatial regional reference framework for sustainability assessment. Pages 249-268 in K. Helming, P. Tabbush, and M. Perez-Soba, editors. Sustainability impact assessment of land use changes. SpringerVerlag, Berlin and Heidelberg, Germany.

Rodrigues, M. J. 2003. European policies for a knowledge economy. Edward Elgar, Cheltenham, Gloucestershire, UK.

Rounsevell, M. D. A., I. Reginster, M. B. Araujo, T. R. Carter, N. Dendoncker, F. Ewert, J. I. House, S. Kankaanpää, R. Leemans, M. J. M. Metzger, C. Schmit, P. Smith, and G. Tuck. 2006. A coherent set of future land use change scenarios for Europe. Agriculture, Ecosystems \& Environment 114:57-68.

Sallnäs, O. 1990. A matrix model of the Swedish forest. Studia Forestalia Suecica 183:23.

Schaldach R., and J. A. Priess. 2008. Integrated models of the land system: a review of modelling approaches on the regional to global scale. Living Reviews in Landscape Research 2. [Online] URL: http://www.livingreviews.org/lrlr-2008-1.

Schelhaas, M. J., J. Eggers, M. Lindner, G. J. Nabuurs, A. Pussinen, R. Päivinen, A. Schuck, P. J. Verkerk, D. C. van der Werf, and S. Zudin. 2007. Model documentation for the European Forest Information Scenario model (EFISCEN 3.1.3). Alterra-rapport 1559 and EFI Technical Report 26. Alterra, Wageningen, The Netherlands, and European Forest Institute, Joensuu, Finland. [Online] URL: http://www2.alterra.wur.nl/Webdocs/ PDFFiles/Alterrarapporten/AlterraRapport1559.pdf ; and [Online] URL: http://www.efi.int/portal/virtu al library/publications/technical reports/26/.

Scholefield, P., L. Firbank, S. Butler, K. Norris, L. M. Jones, and S. Petit. 2009. Modelling the European Farmland Bird Indicator in response to forecast land-use change in Europe. Ecological Indicators11(1):46-51. doi:10.1016/j.ecolind.2009.09.008.

Schößer, B., K. Helming, and H. Wiggering. 2010. Assessing land use change impacts-a comparison of the SENSOR land use function approach with other frameworks. Journal of Land Use Science 5 (2):159-178.
Schulp, C. J. E., G. J. Nabuurs, and P. H. Verburg. 2008. Future carbon sequestration in Europeeffects of land use change. Agriculture, Ecosystems \& Environment 127:251-264.

Sieber, S., M. Müller, P. Verweij, H. Haraldsson, K. Fricke, C. Pacini, K. Tscherning, K. Helming, and T. Jansson. 2008. Transfer into decision support: the Sustainability Impact Assessment Tool (SIAT). Pages 107-130 in K. Helming, P. Tabbush, and M. Perez-Soba, editors. Sustainability impact assessment of land use changes. Springer-Verlag, Berlin and Heidelberg, Germany.

Sieber, S., P. Verburg, M. van Ittersum, and P. Zander. 2010. Model-based systems to support impact assessment—methods, tools and applications. Ecological Modelling 221(18):2133-2135.

Thiel, A. 2009. The use of ex-ante modelling tools in European impact assessment: what role does land use play? Land Use Policy 26(4):1138-1148.

Uthes, S., K. Fricke, H. König, P. Zander, M. van Ittersum, S. Sieber, K. Helming, A. Piorr, and K. Müller. 2010. Policy relevance of three integrated assessment tools - a comparison with specific reference to agricultural policy. Ecological Modelling 18:2136-2152.

Verburg, P., and K. Overmars. 2009. Combining top-down and bottom-up dynamics in land use modeling: exploring the future of abandoned farmlands in Europe with the Dyna-CLUE model. Landscape Ecology 24:1167-1181.

Verburg, P. H., M. D. A. Rounsevell, and A. Veldkamp. 2006. Scenario-based studies of future land use in Europe. Agriculture, Ecosystems \& Environment 114:1-6.

Verburg, P., D. van Berkel, A. van Doorn, M. van Eupen, and H. van den Heiligenberg. 2010. Trajectories of land use change in Europe: a modelbased exploration of rural futures. Landscape Ecology 25:217-232.

Verkerk, P. J., M. Lindner, G. Zanchi, and S. Zudin. 2009. Assessing impacts of intensified biomass removal on deadwood in European forests. Ecological Indicators 11(1):27-35. doi:10.1016/j. ecolind.2009.04.004. 
Verweij, P. J. F. M., M. J. R. Knapen, W. P. de Winter, J. J. F. Wien, J. A. te Roller, S. Sieber, and J. M. L. Jansen. 2010. An IT perspective on integrative environmental modelling: the SIAT case. Ecological Modelling 18:2167-2176.

Volkery, A., and T. Ribeiro. 2007. Prospective environmental analysis of land use development in Europe: from participatory scenarios to long-term strategies. Paper presented at the 2007 Amsterdam Conference on the Human Dimensions of Global Environmental Change, "Earth system governance: theories and strategies for sustainability", Amsterdam, 24-26 May 2007. [Online] URL: http:/ /www.2007amsterdamconference.org/Downloads/ AC2007 Volkery.pdf.

Zhen, L., S. Cao, Y. Wei, O. Dilly, X. Liu, F. Li, H. Koenig, K. Tscherning, and K. Helming. 2009. Comparison of sustainability issues in two sensitive areas of China. Environmental Science \& Policy 12 (8):1153 -1167. 